\title{
IMPACTO DOS MONITORES DE VÍDEO NA PRODUTIVIDADE E NA SAÚDE
}

\author{
LUIZ BUENO DA SILVA ${ }^{1}$
}

SILVA, L.B. da. Impacto dos monitores de vídeo na produtividade e na saúde. Semina: Ci. Exatas/Tecnológicas, v. 16, n. 4, p. 554-557, dez. 1995.

RESUMO: Este artigo propõe aos usuários de VDT, especialmente aqueles que ficam por muito tempo perto deles, alguns cuidados importantes que devem tomar: - O seu VDT tem uma imagem muito pequena? Sem muito brilho? É necessário esperar muito tempo enquanto a imagem está sendo reconstruída após alguma modificação? - A sua tela oscila?- Você pode ver o reflexo do seu rosto ao invés de uma imagem clara na tela? O seu ambiente de trabalho é apropriado levando em consideração os aspectos físico, de equipamento e instalação? - Você tem motivação para trabalhar? Estas e outras questões são levantadas objetivando tornar claro e minimizar problemas causados pelo VDT, e maximizar a produtividade sem afetar sua saúde.

PALAVRAS-CHAVE: Ciência e tecnologia; Ergonomia; Saúde no trabalho; Produtividade.

I - Introdução

Nós passamos da era industrial para a era da informação. Milhões de pessoas no mundo inteiro estão comprometidas com a informação. Este compromisso se deve ao fato de que inúmeras pessoas despendem, pelo menos, um terço do dia em trabalhos vinculados a empresas industriais de porte elevado, inerentes a setores primário, secundário e terciário. Estão, também, ligadas a microempresas e a empresas estatais e federais. Observa-se que a informação é substancialmente trabalhada e perpassada de maneira instantânea, haja vista a necessidade de se obter um produto emergente de um trabalho qualitativo e eficaz. Isto quer dizer que a maioria dessas pessoas estão, de alguma forma, por um tempo grande, diante dos monitores de vídeo [5].

Sem querer mudar a ótica deste raciocínio, mas sim elastecer o dimensionamento da informação no mundo de hoje, vamos dar algumas características que referendam esta preocupação em epígrafe. A Internet é uma rede mundial de computadores que cresceu $300 \%$ no ano passado (1994) e neste ano (1995), segundo as estimativas, a rede crescerá $900 \%$. Até a semana passada, a rede interligava mais de 40 milhões de pessoas em mais de 100 países, do Uruguai aos Estados Unidos, da Lituânia ã Inglaterra. A Internet vem crescendo mais de $10 \%$ ao mês desde meados do ano passado e terá provavelmente 400 milhões de usuários até o final deste ano. A explosão se deu em decorrência de avanços tecnológicos formidáveis nos processos de busca de informação na rede. Milhões de pessoas separadas por milhares de quilômetros conversam horas a fio teclando suas frases nos computadores; elas podem consultar um livro ou um documento em 2000 bibliotecas que podem ser acessadas à distância, 24 horas por dia; cientistas separados no tempo e no espaço trabalham em projetos comuns, compartilhando uma mesma tela [ 1 ].

Dentro deste contexto existe uma preocupação com a produtividade e a saúde dessas pessoas (- que passam horas diante dos monitores de vídeo). Um monitor pobre, sem recursos ideais; ambiente inadequado e outros fatores que fazem a sincronia entre a máquina e o homem, podem interferir no sucesso de horas e horas de trabalho. Um monitor para ser satisfatório tem que possuir uma combinação de recursos úteis e um projeto ergonômico - fácii de ser utilizado e agradável aos olhos [3,8]. E é pensando na qualidade de um trabalho salutar, advindo de profissionais que requerem um tempo maior diante dos monitores de vídeo, que enumeraremos algumas considerações que irão clarificar e minimizar alguns problemas causados por eles.

\section{Problemas Visuais.}

As pessoas que usam computadores de forma intensiva sentem, nos olhos, um desgaste ocular que se manifesta de várias formas: visão turva, olhos irritados, cansaço visual, dor de cabeça durante ou após o uso de monitores, visão dupla, alteração na percepção de cores, dor nas costas, fadiga, irritação,... Um estudo

1 - Universidade Federal da Paraíba, CT, Curso de Pós-Graduação em Engenharia de Produção - 58.051-970 - João Pessoa - PB, Brasil. 
realizado nos EUA em 1990 pelo National Research Council e a National Academy of Science revelou que $50 \%$ dos usuários profissionais de VDTs (Vídeos Displays Terminais) pesquisados apresentavam ao menos um destes sintomas [ 5 ].

Estudos já realizados, inclusive explanados em conferências, mencionam que um pré-requisito fundamental para profissionais que requerem um tempo maior diante dos monitores de vídeo é através de uma solução ergonômica: elaboração de um projeto (design e layout) adequado ao ambiente de trabalho [2 ].

\section{Visão do operador}

Para que um usuário tenha habilidade para ver, alguns fatores são importantes: acuidade visual, acomodação, convergência e percepção das cores.

Acuidade visual - É a capacidade visual para discriminar pequenos detalhes. Ela depende de muitos fatores, sendo os dois mais importantes a iluminação e o tempo de exposição. Dentro dos níveis de iluminação normalmente encontrados, a acuidade visual varia linearmente com o aumento logarítimico da intensidade luminosa. Entretanto, luzes muito fortes prejudicam a acuidade, porque provocam a contração da pupila (a abertura da pupila aumenta na penumbra e se reduz sob luz forte) [4, 7 ].

Acomodação - É a capacidade de cada olho em focalizar objetos a várias distâncias. Isso torna-se possível pela mudança da forma do cristalino (o cristalino

\section{COR DO CARACTER}

Preto

Branco

Amarelo

Ciano

Verde

Magenta

Vermelno

Azul

\section{RECOMENDADO}

Ginza, Branco, Amarelo, Ciano, Magenta, Vermelho

Preto, Verde, Magenta, Vermelho, Azul

Preto, Magenta, Vermelho

Cinza, Preto, Azul

Cinza, Branco, Amarelo

Cinza, Preto, Branco, Ciano, Azui

Cinza, Preto, Branco, Amarelo, Ciano

Cinza, Branco, Ciano fica atrás da pupila, funciona como a lente de uma máquina fotográfica), que fica mais grosso e curvo para focalizar objetos próximos e mais delgado para focalizar objetos distantes. Para focalizar objetos próximos, há um esforço maior da musculatura em manter o cristalino curvo e, com a idade, o cristalino vai se endurecendo, dificultando essa acomodação [ 4, 7 ].

Convergência - É a capacidade dos dois olhos se moverem coordenadamente para focalizar o mesmo objeto. A menor distância para a convergência situa-se em torno de $10 \mathrm{~cm}$ e não é muito afetada pela idade. Os olhos percebem os objetos de ângulos ligeiramente diferentes e, portanto, formam duas imagens diferentes entre si, que são integradas no cérebro, dando a impressão de profundidade ou terceira dimensão [ 4 ].

Percepção de cores - A luz pode ser definida como sendo energia que se propaga através de ondas eletromagnéticas. O olho humano é sensível a radiações eletromagnéticas na faixa de 400 a $750 \mathrm{~nm}$, mas não é igualmente sensível para todos esses comprimentos de onda. A sensibilidade máxima ocorre em torno de 555 $\mathrm{nm}$, o que corresponde à cor verde-amarela, para o olho adaptado à luz. Para o olho adaptado ao escuro, essa sensibilidade máxima situa-se em torno de $510 \mathrm{~nm}$, mais próximo da azul. Os caracteres vermelhos e azuis são os piores para a leitura. As cores ideais são as que estão na faixa central do espectro luminoso: verde, amarelo e laranja. Caso se queira modificar as cores dos programas, há algumas sugestões ergonômicas na tabela abaixo [ 5,6 ].

\section{COR DO FUNDO}

\section{EVITAR}

Azul

Amarelo, Cinza

Verde

Branco

Ciano, Vermeltio, Azul

Vermelho

Verde, Magenta, Azul

Preto, Verde, Vermelho 


\section{Ofuscamento.}

Quando um objeto é mais brilhante que o fundo, ele é facilmente percebido, mas se ocorrer o inverso, haverá uma redução da eficiência visual devido ao ofuscamento. Este é produzido pela presença de luzes, janelas ou áreas excessivamente brilhantes em relação ao nível geral do ambiente, ao qual o olho foi acostumado. Para diminuir consideravelmente o ofuscamento, a medida mais eficiente é eliminar a fonte de brilho do campo visual. Outras medidas aconselháveis consistem em reduzir a fonte de brilho e o brilho refletido [4 ].

\section{Fadiga Visual}

Ela é provocada principalmente pelo esgotamento dos pequenos múscuios ligados ao globo ocular, responsáveis pela movimentação, fixação e focalização dos olhos. Ela provoca tensão e desconforto. Os olhos ficam avermelhados, começam a lacrimejar, e a freqüência de piscar vai aumentando. Muitas vezes a imagem perde a nitidez ou se duplica. Em grau mais avançado, a fadiga visual provoca dores de cabeça, náuseas, depressão e irritabifidade emocional- Ela é decorrente de vários fatores: fixação de detalhes, iluminação inadequada, pouco contraste (pouca diferença entre a figura e o fundo), pouca definição, objetos em movimento e má postura.

Rara evitar a fadiga visual deve haver um cuidadoso planejamento da iluminação, assegurando a focalização do objeto a partir de uma postura confortável. A luz deve ser planejada também para não criar sombras, ofuscamento ou reflexos indesejáveis.

Uma outra observação a ser feita é com relação à idade. Com o avanço da idade há uma redução no tamanho da pupila, diminuindo assim a quantidade de luz que penetra nos olhos. Consequentemente para a mesma intensidade de luz, a quantidade que penetra nos olhos diminui a um terço. Assim sendo, pessoas mais idosas precisam de mais luz para prevenir a fadiga visual [ 2, 4, 7] .

\section{Motivação.}

A motivação nasce das necessidades intrínsecas, sendo compreendida como algo íntimo de cada indivíduo. A motivação pode servir-se de fatores existentes no meio ambiente como meios de satisfazer uma necessidade íntima, mas isso não significa que sua compreensão possa ser reduzida à busca desses fatores em si mesmos. A grande preocupação não deve ser a de buscar aquilo que deve ser feito para motivar as pessoas, mas deve estar particularmente orientada no sentido da busca de estratégias que visam evitar a desmoíivação. Uma pessoa motivada produz mais e melhor. Sofre menos os efeitos da fadiga. Não precisa de muita supervisão, pois procura, por si mesmo, resolver os problemas para alcançar os objetivos [4 ].

\section{Posto de trabalho.}

É necessário que as cadeiras tenham encostos com inclinação regulável entre 90 e 120 graus. Deve-se evitar cadeiras do tipo tradicional, pois estas têm encostos muito pequenos, não permitem uma postura mais relaxada, descarregando o peso das costas sobre o encosto. Ter altura do assento regulável, bordas do assento arredondadas, pouco estofamento, ser giratória, amortecimento vertical e cinco pés com rodas, são outras características desejáveis visando um melhor conforto ao usuário [ 4 ].

\section{Um monitor de vídeo ideal.}

Vamos comentar sobre alguns componentes que devem fazer parte de um monitor de vídeo desejável $[3,8]$ :

a) As telas nao podem apresentar curvas. E melhor que sejam planas. As imagens nas telas planas tendem a ser menos distorcidas e mais agradáveis aos olhos.

b) Há fabricantes de monitores medindo suas telas pelo tamanho do tubo de imagem. É mais eficaz medir pelo tamanho da imagem, pois uma tela de 14" fornece apenas uma área de visualização de 12", e esta área não é muito recomendável, por exemplo, para os usuários da Microsoft Windows. Recomenda-se, para uso geral, uma tela de 17", pois oferece 15" de área de visualização. c) Quanto menor for o dot pitch (espaço entre dois pontos de fósforo da mesma cor em um pixel) mais nítida será a imagem produzida.

d) Os recursos dos controles digitais fornecem um refinamento mais preciso sobre a imagem da tela, configurações e memória.

e) A multivarredura é um recurso que permite a um monitor aceitar sinais em qualquer freqüência dentro da sua largura de banda (- faixa de freqüência que os componentes eletrônicos de um determinado dispositivo podem trabalhar. Quanto maior for a largura de banda do monitor mais altas serão as freqüências em que ele pode trabalhar e, consequentemente, produzirar-se-á uma melhor imagem na tela). Se um monitor for capaz de sincronizar seus circuitos internos eletrônicos em qualquer freqüência de varredura, com certeza o usuário terá mais flexibilidade para produzir um trabalho mais eficiente.

f) Nem sempre é bom usar uma máscara anti-reflexiva sobre a tela. Às vezes essa máscara escurece e distorce as imagens na tela.

g) As telas não entrelaçadas desenham as linhas serialmente, o que reduz bastante as oscilações da tela. h) Outro fator que pode evitar oscilações na tela e, consequentemente, gerar um conforto visual para o usuário, é configurando a taxa de renovação (quantidade de tempo gasto para redesenhar a tela) do monitor para um valor superior aos $70 \mathrm{~Hz}$ padrão. A VESA (Vídeo Electronics Standards Association) descobriu que uma taxa de renovação de $60 \mathrm{~Hz}$ coincide exatamente com a taxa de renovação de uma lâmpada fluorescente padrão, resultando num efeito de pleno desconforto para 
o usuário.

i) Muitos não dão importância à carga eletrostática! A medida que os elétrons se chocam com o interior da tela, o monitor freqüentemente cria uma carga eletrostática, ficando consequentemente empoeirado, o que pode reduzir a qualidade da imagem. A cobertura antiestãtica reduz a carga estática, bem como as ocorrências de uma descarga se o usuário tocar na tela. j) Dependendo do trabalho que se está fazendo, há telas mais apropriadas. Por exemplo, se estivermos diagramando uma página é conveniente que a tela seja giratória, pois isto evita que usuário fique disperso por tempos maiores nas telas típicas ou convencionais.

k) Se a base for giratória e inclinável oferecerá um conforto extremo para o usuário.

\section{Emissão de radiação.}

Segundo o Dr. John Hunt, CNEN/DEMIN/DIMEX/ 1RD, Rio de Janeiro, existem normas de fabricação de vídeos que asseguram que o nível de radiação ionizante emitido por eles não representa um risco à saúde dos usuários. Os níveis são tão baixos que o controle do uso dos vídeos não é considerado parte da radioproteção (numa distância de $50 \mathrm{~cm}$ do monitor a taxa de dose efetiva estaria dentro da variação natural da radiação ambiental).

Existem estudos, ainda não comprovados, questionando os efeitos prejudiciais ou não das interferências eletromagnéticas. Mesmo assim é aconselhável um monitor padrão sueco MPR II $[3,8]$.

\section{II - Conclusão}

Acreditamos que há muitas questões que envolvem trabalhos com monitores de vídeo a serem respondidas. Uma sugestão ergonômica importante está ligada ao design e layout do ambiente de trabalho que, por sua vez, pode contribuir consideravelmente para a solução de alguns problemas relativos ao desgaste ocular.

Há muitas citações em publicações científicas sobre a associação das radiações ionizantes e nãoionizantes com o trabalho em monitores de vídeo. Existe uma grande preocupação desta associação ser prejudicial ao usuário, mas, na realidade, nada ainda foi comprovado [2, 3, 7, 8 ].

Uma recomendação significativa às pessoas que produzem informação, a profissionais que trabalham intensivamente com computadores e aos produtores de monitores de vídeo, é obedecer as normas regulamentadoras da Segurança e Medicina do Trabalho. Estas normas prevêem riscos ambientais. Elas estabelecem parâmetros, permitindo a adaptação das condições de trabalhos às características psicofisíológicas dos trabalhadores, de modo a proporcionar um máximo de conforto, segurança e desempenho eficiente [ 9 ].

SILVA, L.B. da. Impact of the video monitors on productivity and health. Semina: Ci. Exatas/Tecnológicas, v. 16, n. 4 , p. 554-557, Dec. 1995.

ABSTRACT: This.article proposes to VDT users, especially those who stay for a long period dose to them, some important cares: - Does your VDT have a very small image ? Without much brightness? Is it necessary to wait for a long time white image is being rebuilt after any change? Does your screen oscillate? Can you see your face reflection instead of a clear image on screen? Is your environment fít to work considering physical, equipment and installation aspects? Do you have motivation to work? These and other questions are raised aiming to clarify and minimize problems caused by VDT, and maximize the productivity without affecting your health,

KEY-WORDS: Science and Technology; Ergonomics; Health on Work; Productivity.

\section{REFERÊNCIAS BIBLIOGRÁFICAS}

ALCÂNTARA, Euripides. A rede que abraça todo o planeta. Revista Veja, São Paulo, ed. 1381, ano 28, n. 9, 1995. p. $48-58$.

BONNELL, J. A. Vdt's and ealth fact or fancy? Work with display units 86 ; edited by Bengt Knave and Per-Gunnar Widebäck. Stockholm: North-Holland, 1986. p. 3-5.

LENNON, Anthony J. 62 monitores coloridos: grandes e bonitos. Byte Brasil, São Paulo, v. 4, n. 1, 1994. p. 88-101.

LIDA, Itiro. Ergonomia projeto e produção. São Paulo: Edgard Blücher Ltda, 1992. 462p.

MELLO, Alexandre Bandeira de. O computador e o desgaste visual: preocupa-se com a sua saúde. CPUPC,
Rio de Janeira, n. 10, p. 10.22-10.36. 1994.

POT, Frank, PADMOS, Pieter, BROUWERS, Alfred. Deteminants of the vatu operator's well-being Work with display units 86 ; edited by Beng Knave and Per-Gunnar Wideback. Stockholm: North-Holand, 1986. p. 16-25.

SUESS, Michael J. Health impact of work with visual display teminals. Work with display units 86; edited by Bengt Knave and Per-Gunnar wideback. Stockholm: North-Holland, 1986. p. 6-15.

ULANOFF, Lance. O monitor perfeito. PC Magazine Brasil, Sảo Paulo, v. 5, n. 1, p. 94-106, jan. 1995.

VIEIRA, Jair Lot. Segurança e medicina do trabatho. São Paulo: Edipro, 1992. 400p. 